\title{
Vitamin D Deficiency and Risk for Cardiovascular Disease
}

\author{
Suzanne E. Judd, MPH, PhD ${ }^{1}$ and Vin Tangpricha, MD, $\mathrm{PhD}^{2,3,4}$ \\ ${ }^{1}$ Department of Biostatistics, University of Alabama at Birmingham, Birmingham, Alabama \\ ${ }^{2}$ Division of Endocrinology, Metabolism and Lipids, Department of Medicine, Emory University \\ School of Medicine, Atlanta, Georgia \\ ${ }^{3}$ Center for Clinical and Molecular Nutrition, Department of Medicine, Emory University School of \\ Medicine, Atlanta, Georgia \\ ${ }^{4}$ Atlanta VA Medical Center, Decatur, Georgia
}

\section{Abstract}

\begin{abstract}
Vitamin D is an important prohormone for optimal intestinal calcium absorption for mineralization of bone. Because the vitamin D receptor is present in multiple tissues, there has been interest in evaluating other potential functions of vitamin D, particularly, in cardiovascular diseases (CVD). Cross-sectional studies have reported that vitamin D deficiency is associated with increased risk of CVD, including hypertension, heart failure, and ischemic heart disease. Initial prospective studies have also demonstrated that vitamin D deficiency increases the risk of developing incident hypertension or sudden cardiac death in individuals with preexisting CVD. Very few prospective clinical studies have been conducted to examine the effect of vitamin D supplementation on cardiovascular outcomes. The mechanism for how vitamin D may improve CVD outcomes remains obscure; however, potential hypotheses include the downregulation of the renin-angiotensinaldosterone system, direct effects on the heart, and vasculature or improvement of glycemic control. This review will examine the epidemiologic and clinical evidence for vitamin D deficiency as a cardiovascular risk factor and explore potential mechanisms for the cardioprotective effect of vitamin D.
\end{abstract}

\section{Key Indexing Terms \\ Vitamin D; Cholecalciferol; Ergocalciferol cardiovascular disease; Hypertension}

\begin{abstract}
The classic function of vitamin $\mathrm{D}$ is to increase the intestinal absorption of calcium for proper mineralization of bone. ${ }^{1}$ The active form of vitamin $\mathrm{D}, 1,25$-dihydroxyvitamin $\mathrm{D}(1,25$ $\left.(\mathrm{OH})_{2} \mathrm{D}\right)$, acts as a steroid hormone by binding to the vitamin D receptor (VDR), which is present in many cells throughout the body, including cardiomyocytes, ${ }^{2}$ vascular smooth muscle ${ }^{3}$ and endothelium ${ }^{4}$. Recent evidence has demonstrated that individuals deficient in vitamin D are more likely to have cardiovascular disease (CVD) or are at risk of developing incident CVD. The mechanism for how vitamin D may protect individuals from CVD has not been fully elucidated. Several mechanisms have been proposed, including negatively regulating renin to lower blood pressure, improving vascular compliance, decreasing parathyroid hormone (PTH) levels, and improving glycemic control. The purpose of this review
\end{abstract}

Correspondence: Vin Tangpricha, MD, PhD, Emory University Division of Endocrinology, Metabolism and Lipids, 101 Woodruff Circle NE, Woodruff Memorial Research Building, Room 1301, Atlanta, GA 30322 (vin.tangpricha@emory.edu).

Presented, in part, as a State-of-the-Art Lecture at the Joint Meeting of the Southern Society for Clinical Investigation and International Academy of Cardiovascular Sciences/North America, February 12-14, 2009. 
is to summarize the epidemiologic and early preclinical and clinical evidence for a protective role for vitamin D in the cardiovascular system.

\section{Physiology of Vitamin D}

Vitamin $\mathrm{D}$ can be produced in the skin as vitamin $\mathrm{D}_{3}$ on exposure to ultraviolet-B (UVB) from the sun or obtained from the diet as vitamin $\mathrm{D}_{2}$ or vitamin $\mathrm{D}_{3}$. After vitamin $\mathrm{D}$ enters the body, it circulates bound to vitamin D-binding protein and is rapidly converted to its major circulating form, 25-hydroxyvitamin D $(25(\mathrm{OH}) \mathrm{D})$, by the liver. Under the influence of PTH, 25(OH)D is converted by the 1-alpha-hydroxylase (1 $\alpha$-OHase) in the kidney to form the hormonal form of vitamin $\mathrm{D}, 1,25$-dihydroxyvitamin $\mathrm{D}\left(1,25(\mathrm{OH})_{2} \mathrm{D}\right)$. Other tissues in the body have the $1 \alpha$ OHase and can convert $25(\mathrm{OH}) \mathrm{D}$ to $1,25(\mathrm{OH})_{2} \mathrm{D} .{ }^{5}$ However, only the renal $1 \alpha$-OHase significantly contributes to circulating $1,25(\mathrm{OH})_{2} \mathrm{D}$ levels. It is speculated that the presence of the extrarenal $1 \alpha$-OHases allow $25(\mathrm{OH}) \mathrm{D}$ to be converted to $1,25(\mathrm{OH})_{2} \mathrm{D}$ to work as a paracrine or autocrine hormone.

Circulating $1,25(\mathrm{OH})_{2} \mathrm{D}$ enters the target cell, either in its free form or facilitated by megalin, and binds to the VDR in the cytoplasm, which then translocates to the nucleus and heterodimerizes with the retinoic $\times$ receptor. $^{6}$ The $1,25(\mathrm{OH})_{2} \mathrm{D}$-VDR-retinoic $\times$ receptor complex then binds to vitamin D response elements on DNA to increase transcription of vitamin D-regulated genes. Classic functions regulated by vitamin D include genes important for mineralization of bone and calcium transport in the intestine. ${ }^{7}$ Nonclassic or novel functions of vitamin $\mathrm{D}$ under investigation include genes important for innate immunity, cancer proliferation, muscle (both skeletal and smooth) function, and endothelial cell proliferation. ${ }^{5}$

Vitamin D status is best determined by a serum $25(\mathrm{OH}) \mathrm{D}$ as opposed to $1,25(\mathrm{OH})_{2} \mathrm{D}$, for several reasons including (1) its long circulating half life ( $\sim 3$ weeks versus $\sim 8$ hours); (2) the concentration of $25(\mathrm{OH}) \mathrm{D}$ is $1000 \times$ higher in circulation compared with $1,25(\mathrm{OH})_{2} \mathrm{D}(\mathrm{ng} / \mathrm{mL}$ versus $\mathrm{pg} / \mathrm{mL}$ ); and (3) the production of $1,25(\mathrm{OH})_{2} \mathrm{D}$ is mainly under the influence of PTH, which tightly regulates calcium levels. Thus, $1,25(\mathrm{OH})_{2} \mathrm{D}$ levels could be elevated in individuals with severe vitamin $\mathrm{D}$ deficiency to maintain normal serum calcium levels. As a mediator of CVD, it is believed that $25(\mathrm{OH}) \mathrm{D}$ is the best biomarker to describe vitamin $\mathrm{D}$ status, although this has not been proven.

\section{Cross-Sectional and Epidemiologic Evidence Evaluating Vitamin D Status and CVD Risk}

Several observations in the early 1980s and 1990s suggested that an environmental factor, such as vitamin D, could explain differences in mortality from ischemic heart disease (IHD). Fleck recognized higher mortality rates with increased distance from the equator. ${ }^{8}$ Grimes et al ${ }^{9}$ also recognized that mortality from IHD was inversely proportional to the amount of hours of sunlight in the United Kingdom. He proposed vitamin D as a protective factor by regulating serum cholesterol levels or by inhibiting Chlamydia pneumoniae, once thought to be a cause of coronary heart disease. Douglas et $\mathrm{al}^{10}$ recognized that incidence and mortality rates from coronary heart disease demonstrated a strong seasonal pattern with higher rates in the winter, when vitamin D levels are lowest. Rostand ${ }^{11}$ reported that blood pressure increased with increasing distance from the equator and suggested that cutaneously synthesized vitamin D could be playing a role in the regulation of blood pressure.

The National Health and Nutritional Examination Surveys (NHANES) (1988-1994, 20002004) conducted in the United States have provided a means to explore cross-sectional associations between vitamin D status and CVD. Kendrick et a ${ }^{12}$ reported that individuals surveyed in NHANES 1988-1994 with vitamin D deficiency $(25(\mathrm{OH}) \mathrm{D}<20 \mathrm{ng} / \mathrm{mL})$ had higher 
prevalence of self-reported angina, myocardial infarction, and heart failure compared with individuals with higher levels of vitamin D [OR (95\% CI) $1.20(1.01,1.36)]$. In the most recent NHANES 2000-2004 survey, vitamin D deficiency (25(OH)D $<20 \mathrm{ng} / \mathrm{mL}$ ) was associated with increased prevalence of self-reported coronary heart disease, heart failure, and peripheral vascular disease. ${ }^{13}$ Several cardiovascular risk factors have been associated with lower vitamin D status, including hypertension, diabetes, elevated body mass index $(>30)$, elevated triglyceride level, and microalbuminuria in NHANES 1988-1994. ${ }^{14,15}$ Prevalence of peripheral arterial disease is also increased comparing lowest quartile of $25(\mathrm{OH}) \mathrm{D}$ to highest quartile of $25(\mathrm{OH}) \mathrm{D} .{ }^{16} \mathrm{Judd}$ et $\mathrm{al}^{17}$ determined, in non-hypertensive individuals from NHANES 1988-1994, that optimal vitamin D status (>32 $\mathrm{ng} / \mathrm{mL}$ ) provided a $20 \%$ reduction in the rate of blood pressure rise with age. In contrast, smaller cross-sectional studies from Germany ${ }^{18}$ and the Netherlands ${ }^{19}$ have not been able to confirm an association between vitamin D status and blood pressure in older adults.

Melamed et $\mathrm{al}^{20}$ examined all-cause mortality by quartile of $25(\mathrm{OH}) \mathrm{D}$ and found that the lowest quartile of $25(\mathrm{OH}) \mathrm{D}$ had significantly increased adjusted mortality rate ratios $(95 \% \mathrm{CI}) 1.28$ (1.11-1.48) compared with individuals with the highest quartile of 25(OH)D. There was a trend toward increased mortality rate in the lowest quartile of $25(\mathrm{OH}) \mathrm{D}$ due to cardiovascular mortality; however, this did not reach statistical significance [mortality rate ratios $(95 \% \mathrm{CI})$ $1.22(0.90-1.65)]$. Thus, several epidemiologic findings seem to suggest that poor vitamin D status is associated with poor cardiovascular outcomes.

\section{Cohort and Case-Control Studies Evaluating Vitamin D Status and CVD Risk}

Several studies have evaluated a baseline measurement of vitamin D status and prospectively evaluated long-term cardiovascular outcomes in subjects with no history of CVD. During a 10-year follow-up period, men in the Health Professionals Follow-up Study without previous CVD and vitamin D deficiency $(25(\mathrm{OH}) \mathrm{D}<15 \mathrm{ng} / \mathrm{mL})$ exhibited a 2-fold increased rate of myocardial infarction. ${ }^{21}$ In the Framingham Offspring Study, subjects with no history of CVD and severe vitamin D deficiency $(25(\mathrm{OH}) \mathrm{D}<10 \mathrm{ng} / \mathrm{mL})$ experienced a hazard ratio of 1.80 (95\% CI, 1.05-3.08) for developing a first cardiovascular event after 5 years of follow-up compared with subjects with higher levels of $25(\mathrm{OH}) \mathrm{D}(>15 \mathrm{ng} / \mathrm{mL}){ }^{22}$

Vitamin D status and risk of CVD has also been evaluated in subjects with established CVD or end-stage kidney disease. In more than 3000 subjects undergoing coronary angiography, severe vitamin $\mathrm{D}$ deficiency $(25(\mathrm{OH}) \mathrm{D}<10 \mathrm{ng} / \mathrm{mL})$ had 3 to 5 times risk of dying from sudden cardiac death or heart failure during a 7-year follow-up period compared with optimal levels of vitamin $\mathrm{D}(25(\mathrm{OH}) \mathrm{D}>30 \mathrm{ng} / \mathrm{mL}) .{ }^{23}$ Further, in these same subjects, vitamin $\mathrm{D}$ deficiency imparted a $50 \%$ increase in fatal stroke. ${ }^{24}$ Subjects in the lowest quartile for $25(\mathrm{OH}) \mathrm{D}$ had increased hazard ratios for all-cause and cardiovascular mortality compared with subjects in the highest quartile for $25(\mathrm{OH}) \mathrm{D} .{ }^{25}$ Similar findings have been reported in incident hemodialysis patients. ${ }^{26}$ An earlier and smaller study from India did not establish any benefit from having optimal levels of $25(\mathrm{OH}) \mathrm{D}$ in subjects with established CVD. ${ }^{27}$ In contrast, they reported that very high levels of $25(\mathrm{OH}) \mathrm{D}(>89 \mathrm{ng} / \mathrm{mL})$ were associated with increased risk of IHD.

Several studies have examined the relationship between vitamin D status and incident hypertension. Men and Women participating in the Health Professionals Follow-up Study and the Nurses' Health Study with vitamin D deficiency ( $<15 \mathrm{ng} / \mathrm{mL})$ had 3- to 6-fold increased risk of developing incident hypertension during a 4-year follow-up period compared with subjects with optimal vitamin D status. ${ }^{28}$ Similar protection with having optimal vitamin D status and the development of incident hypertension was seen in the Nurses Health Study II, a group of younger female subjects. ${ }^{29}$ A large cohort study from the United Kingdom also 
reported that vitamin D status was inversely related to the development of components of the metabolic syndrome, including hypertension. ${ }^{30}$

\section{Randomized Controlled Trials of Vitamin D Supplmentation and Risk of CVD}

Given the early epidemiologic associations between vitamin D and hypertension, early studies of vitamin $\mathrm{D}$ supplementation have focused on vitamin $\mathrm{D}$ as a potential antihypertensive agent. A randomized controlled trial conducted in elderly German women demonstrated that modest amounts of vitamin D (400 IU) plus calcium given during an 8-week period significantly reduced systolic blood pressure by $9 \% .{ }^{31}$ Krause et al ${ }^{32}$ randomized 18 subjects with stage I hypertension to ultraviolet-A exposure to skin (which does not produce vitamin $\mathrm{D}$ ) and to UVB exposure to skin (which produces vitamin $\mathrm{D}_{3}$ ) and demonstrated that systolic and diastolic blood pressure significantly decreased after 6 weeks of therapy in those subjects receiving UVB therapy, suggesting that cutaneously produced vitamin D resulted in lowered blood pressure. In contrast, several smaller studies conducted primarily in elderly subjects have demonstrated no effect of vitamin D supplementation on blood pressure in Denmark, ${ }^{33}$ in Taiwan, ${ }^{34}$ and in the United Kingdom. ${ }^{35}$ The Women's Health Initiative (WHI) Study conducted in the United States demonstrated no significant difference in systolic or diastolic blood pressure in women randomized to calcium and vitamin D ( $400 \mathrm{IU})$ at the end of 7 years of follow-up. Therefore, studies on vitamin D supplementation have not consistently demonstrated a positive effect on regulating blood pressure. However, several caveats should be noted including relatively low doses of vitamin D used as the intervention (typically 400 IU), most studies did not demonstrate adequate improvement of $25(\mathrm{OH}) \mathrm{D}$ to optimal levels (>30 ng/mL), and adherence was low, particularly, in the WHI study.

Very few studies have been conducted to evaluate vitamin D supplementation on risk of cardiovascular mortality. Two studies prospectively examined vitamin D supplementation on cardiovascular mortality. In the WHI, women randomized to vitamin D 400 IU daily and 1000 $\mathrm{mg}$ of calcium had no difference in all-cause or cardiovascular mortality ${ }^{36}$ In a European study by Trivedi et al, ${ }^{37}$ elderly individuals receiving a daily equivalent dose of $800 \mathrm{IU}$ of vitamin D did not have improved cardiovascular survival compared with controls. A recent metaanalysis examined 9 randomized controlled trials and found an $8 \%$ reduction in all-cause mortality with supplementation of very modest amounts of vitamin D ( $500 \mathrm{IU})$. In this metaanalysis, cardiovascular mortality was reported only by 2 studies as discussed above. ${ }^{36,37}$ The Institutes of Medicine currently recommend a daily intake of 400-600 IU of vitamin D for adults. Several experts believe this intake level is inadequate for adults to maintain a optimal vitamin D status and a daily intake of close to $1000 \mathrm{IU}$ of vitamin D is required to maintain health. ${ }^{38}$

\section{Proposed Protective Mechanisms for Vitamin D in CVD}

The mechanism for how vitamin D may protect against CVD has not been fully elucidated. Proposed mechanisms include effects on the renin-angiotensin system, on glycemic control, inflammatory cytokines, direct effects on the vasculature and regulation of PTH levels, and calcium deposition in vascular smooth muscle. ${ }^{22,39,40}$ Studies to examine these mechanisms have been conducted mainly in preclinical studies with very little information available from clinical trials.

\section{Vitamin D as a Negative Regulator of Renin}

Pioneering work by Yan Chun Li at the University of Chicago has reinvigorated interest in vitamin $\mathrm{D}$ as an antihypertensive agent. His group clearly established that VDR knockout mice have elevated blood pressure, cardiac hypertrophy, and elevated activation of the reninangiotensin-aldosterone system (RAAS), which can be reversed with an angiotensin- 
converting enzyme inhibitor. ${ }^{41}$ Furthermore, wild-type mice given injections of 1,25 $(\mathrm{OH})_{2} \mathrm{D}_{3}$ demonstrated suppression of renin mRNA expression. ${ }^{41}$ Several novel vitamin D analogs have also been demonstrated to inhibit renin expression in vitro, possibly leading to the development of specific cardioselective vitamin D compounds for the treatment of hypertension without calcemic effects. ${ }^{42}$ In a follow-up study, Li et al demonstrated that 1,25 $(\mathrm{OH})_{2} \mathrm{D}$ inhibits renin gene expression by sequestering cyclic adenosine monophosphate response element binding, a necessary factor for the transcription of renin mRNA. ${ }^{43}$ These very intriguing observations have yet to be translated in rigorous randomized controlled trials of vitamin D or its analogs on hypertension and signaling of the RAAS.

\section{Vitamin D as a Factor in Improving Insulin Sensitivity}

The pancreas possesses the VDR and the $1 \alpha$-OHase and, thus, has the vitamin D machinery for circulating $25(\mathrm{OH}) \mathrm{D}$ to be converted to $1,25(\mathrm{OH})_{2} \mathrm{D}$ to work as a paracrine or autocrine hormone Early studies have suggested that vitamin D-deficient rodents are not able to adequately secrete insulin compared with vitamin D-sufficient controls. ${ }^{44}$ Several small observational and case-control studies have been published to suggest that vitamin D deficiency is associated with insulin resistance or impaired insulin secretion. ${ }^{45,46}$ Several studies, including 1 published by Scragg et al, demonstrated that lower vitamin D status was associated with increased risk of diabetes and better insulin sensitivity. ${ }^{47,48}$ In a longitudinal study of Finnish men and women, a $40 \%$ reduction in risk of developing type 2 diabetes was observed after 17 years of follow-up in those with $25(\mathrm{OH}) \mathrm{D}$ levels $>28 \mathrm{ng} / \mathrm{mL}$ at baseline. ${ }^{49}$ One prospective study evaluated the effect of vitamin D supplementation (400 IU daily) on fasting glucose and found that subjects with impaired fasting glucose at baseline had less of a rise in fasting glucose concentrations during a 3-year period compared with subjects randomized to placebo ${ }^{50}$ Taken together, this early evidence suggests that vitamin D may have an important role in regulating glycemic control, which may also contribute to a beneficial effect on cardiovascular outcomes.

\section{Vitamin D as a Direct Factor on Cardiac Tissues and the Vasculature}

A few in vitro and in vivo studies have evaluated the role of vitamin D acting directly on cardiac tissue, especially in response to injury. Rahman et al ${ }^{51}$ demonstrated that matrix

metalloproteinases, proteins that contribute to aberrant cardiomyocyte remodeling in response to injury and atherosclerosis, were upregulated in VDR knockout mice. VDR knockout mice have impaired cardiac relaxation and contractility ${ }^{52}$ and develop left ventricular hypertrophy. 41,53

Clinical studies have evaluated the role of vitamin D directly on the vasculature. A crosssectional study of 52 subjects with end-stage kidney disease demonstrated a significant positive correlation between vitamin $\mathrm{D}$ status and arterial compliance measured by brachial artery flowmediated dilation and a negative correlation between aortic pulse wave velocity, both findings indicating decreased vascular compliance. ${ }^{54}$ Vitamin D (1,25-dihydroxyvitamin D) inhibited profibrotic markers in vitro using mesenchymal multipotent cells, suggesting that vitamin D may also have a direct effect on the vasculature in response to injury. ${ }^{55}$ Diabetic patients who ingested a single large dose of vitamin D (100,000 IU) had significant improvement in endothelial function measured by flow-mediated dilation and decrease in blood pressure. ${ }^{56}$ Finally, a recent randomized controlled trial of vitamin D supplementation in subjects with heart failure demonstrated significant reductions in inflammatory cytokines involved in the pathophysiology of heart failure. ${ }^{57}$ 


\section{CONCLUSION}

Vitamin D insufficiency is very common in the United States and worldwide. Several recent epidemiologic studies have demonstrated a strong association between vitamin D insufficiency and risk of CVD, risk of diabetes and metabolic syndrome. Several prospective studies have suggested that vitamin D deficiency predisposes individuals to increased risk of incident hypertension, IHD, sudden cardiac death, or heart failure. Initial randomized clinical trials of vitamin $\mathrm{D}$ in the treatment of hypertension have yielded mixed results; however, the study design of these trials limits definitive conclusions. No large randomized clinical trials using vitamin $\mathrm{D}$ or its analogs on cardiovascular endpoints have been published to date.

The potential for vitamin D to have a role in the prevention and/or treatment of CVD has some biologic plausibility. Several studies have demonstrated that VDR knockout mice have increased surrogate markers of CVD, including hypertension, left ventricular hypertrophy, and increased proteinuria. One of the leading hypotheses for the protective effects of vitamin D is its negative regulation on the RAAS. Other mechanisms may also include effects on cardiac remodeling, the vasculature, inflammatory markers, and glycemic control.

The results of future trials should provide guidance on how to manage vitamin D status in clinical practice. There are currently no universal guidelines for the screening and treatment of vitamin D insufficiency. Furthermore, the adequate intake levels established by the Institutes of Medicine have been recognized to be inadequate and are currently in revision. In the meantime, it may be prudent to screen individuals who are at highest risk for vitamin D insufficiency (institutionalized elderly, osteoporotic individuals, chronically ill patients, African American patients, especially those with $\mathrm{CVD}^{58}$ ) and treat with vitamin D to a $25(\mathrm{OH})$ $\mathrm{D}$ level of $30 \mathrm{ng} / \mathrm{mL}$. The current evidence does not strongly support screening for vitamin D deficiency in all patients with established CVD or who are at risk for CVD. For the general population, increasing vitamin D status with a daily supplement containing at least $1000 \mathrm{IU}$ may be sufficient, especially in areas with increased latitude from the equator or during the winter months.

\section{Acknowledgments}

This study was supported, in part, by NIH K23 AR054334 (to VT).

\section{References}

1. Khazai N, Judd SE, Tangpricha V. Calcium and vitamin D: skeletal and extraskeletal health. Curr Rheumatol Rep 2008;10:110-7. [PubMed: 18460265]

2. Nibbelink KA, Tishkoff DX, Hershey SD, et al. 1,25(OH)2-vitamin D3 actions on cell proliferation, size, gene expression, and receptor localization, in the HL-1 cardiac myocyte. J Steroid Biochem Mol Biol 2007;103:533-7. [PubMed: 17276054]

3. Wu-Wong JR, Nakane M, Ma J, et al. Effects of Vitamin D analogs on gene expression profiling in human coronary artery smooth muscle cells. Atherosclerosis 2006;186:20-8. [PubMed: 16095599]

4. Merke J, Milde P, Lewicka S, et al. Identification and regulation of 1,25-dihydroxyvitamin D3 receptor activity and biosynthesis of 1,25-dihydroxyvitamin D3. Studies in cultured bovine aortic endothelial cells and human dermal capillaries. J Clin Invest 1989;83:1903-15. [PubMed: 2542376]

5. Holick MF. Vitamin D deficiency. N Engl J Med 2007;357:266-81. [PubMed: 17634462]

6. Rowling MJ, Kemmis CM, Taffany DA, et al. Megalin-mediated endocytosis of vitamin D binding protein correlates with 25-hydroxy-cholecalciferol actions in human mammary cells. J Nutr 2006;136:2754-9. [PubMed: 17056796]

7. Pike JW, Zella LA, Meyer MB, et al. Molecular actions of 1,25-dihydroxyvitamin D3 on genes involved in calcium homeostasis. J Bone Miner Res 2007;22(suppl 2):V16-9. [PubMed: 18290714]

8. Fleck A. Latitude and ischaemic heart disease. Lancet 1989;1:613. [PubMed: 2564129] 
9. Grimes DS, Hindle E, Dyer T. Sunlight, cholesterol and coronary heart disease. QJM 1996;89:579_ 89. [PubMed: 8935479]

10. Douglas AS, Dunnigan MG, Allan TM, et al. Seasonal variation in coronary heart disease in Scotland. J Epidemiol Community Health 1995;49:575-82. [PubMed: 8596091]

11. Rostand SG. Ultraviolet light may contribute to geographic and racial blood pressure differences. Hypertension 1997;30(2 Pt 1):150-6. [PubMed: 9260973]

12. Kendrick J, Targher G, Smits G, et al. 25-Hydroxyvitamin D deficiency is independently associated with cardiovascular disease in the Third National Health and Nutrition Examination Survey [published online ahead of print November 11, 2008]. Atherosclerosis. 10.1016/j.atherosclerosis. 2008.10.033

13. Kim DH, Sabour S, Sagar UN, et al. Prevalence of hypovitaminosis D in cardiovascular diseases (from the National Health and Nutrition Examination Survey 2001 to 2004). Am J Cardiol 2008;102:1540-4. [PubMed: 19026311]

14. Martins D, Wolf M, Pan D, et al. Prevalence of cardiovascular risk factors and the serum levels of 25-hydroxyvitamin D in the United States: data from the Third National Health and Nutrition Examination Survey. Arch Intern Med 2007;167:1159-65. [PubMed: 17563024]

15. Scragg R, Sowers M, Bell C. Serum 25-hydroxyvitamin D, ethnicity, and blood pressure in the Third National Health and Nutrition Examination Survey. Am J Hypertens 2007;20:713-9. [PubMed: 17586404]

16. Melamed ML, Muntner P, Michos ED, et al. Serum 25-hydroxyvitamin D levels and the prevalence of peripheral arterial disease: results from NHANES 2001 to 2004. Arterioscler Thromb Vasc Biol 2008;28:1179-85. [PubMed: 18417640]

17. Judd SE, Nanes MS, Ziegler TR, et al. Optimal vitamin D status attenuates the age-associated increase in systolic blood pressure in white Americans: results from the Third National Health and Nutrition Examination Survey. Am J Clin Nutr 2008;87:136-41. [PubMed: 18175747]

18. Hintzpeter B, Mensink GB, Thierfelder W, et al. Vitamin D status and health correlates among German adults. Eur J Clin Nutr 2008;62:1079-89. [PubMed: 17538533]

19. Snijder MB, Lips P, Seidell JC, et al. Vitamin D status and parathyroid hormone levels in relation to blood pressure: a population-based study in older men and women. J Intern Med 2007;261:558-65. [PubMed: 17547711]

20. Melamed ML, Michos ED, Post W, et al. 25-Hydroxyvitamin D levels and the risk of mortality in the general population. Arch Intern Med 2008;168:1629-37. [PubMed: 18695076]

21. Giovannucci E, Liu Y, Hollis BW, et al. 25-Hydroxyvitamin D and risk of myocardial infarction in men: a prospective study. Arch Intern Med 2008;168:1174-80. [PubMed: 18541825]

22. Wang TJ, Pencina MJ, Booth SL, et al. Vitamin D deficiency and risk of cardiovascular disease. Circulation 2008;117:503-11. [PubMed: 18180395]

23. Pilz S, März W, Wellnitz B, et al. Association of vitamin D deficiency with heart failure and sudden cardiac death in a large cross-sectional study of patients referred for coronary angiography. $\mathrm{J}$ Clin Endocrinol Metab 2008;93:3927-35. [PubMed: 18682515]

24. Pilz S, Dobnig H, Fischer JE, et al. Low vitamin D levels predict stroke in patients referred to coronary angiography. Stroke 2008;39:2611-3. [PubMed: 18635847]

25. Dobnig H, Pilz S, Scharnagl H, et al. Independent association of low serum 25-hydroxyvitamin d and 1,25-dihydroxyvitamin d levels with all-cause and cardiovascular mortality. Arch Intern Med 2008;168:1340-9. [PubMed: 18574092]

26. Wolf M, Shah A, Gutierrez O, et al. Vitamin D levels and early mortality among incident hemodialysis patients. Kidney Int 2007;72:1004-13. [PubMed: 17687259]

27. Rajasree S, Rajpal K, Kartha CC, et al. Serum 25-hydroxyvitamin D3 levels are elevated in South Indian patients with ischemic heart disease. Eur J Epidemiol 2001;17:567-71. [PubMed: 11949730]

28. Forman JP, Giovannucci E, Holmes MD, et al. Plasma 25-hydroxyvitamin D levels and risk of incident hypertension. Hypertension 2007;49:1063-9. [PubMed: 17372031]

29. Forman JP, Curhan GC, Taylor EN. Plasma 25-hydroxyvitamin D levels and risk of incident hypertension among young women. Hypertension 2008;52:828-32. [PubMed: 18838623] 
30. Hyppönen E, Boucher BJ, Berry DJ, et al. 25-Hydroxyvitamin D, IGF-1, and metabolic syndrome at 45 years of age: a cross-sectional study in the 1958 British Birth Cohort. Diabetes 2008;57:298-305. [PubMed: 18003755]

31. Pfeifer M, Begerow B, Minne HW, et al. Effects of a short-term vitamin D(3) and calcium supplementation on blood pressure and parathyroid hormone levels in elderly women. J Clin Endocrinol Metab 2001;86:1633-7. [PubMed: 11297596]

32. Krause R, Bühring M, Hopfenmüller W, et al. Ultraviolet B and blood pressure. Lancet 1998;352:709_ 10. [PubMed: 9728997]

33. Myrup B, Jensen GF, McNair P. Cardiovascular risk factors during estrogen-norethindrone and cholecalciferol treatment. Arch Intern Med 1992;152:2265-8. [PubMed: 1332634]

34. Pan WH, Wang CY, Li LA, et al. No significant effect of calcium and vitamin D supplementation on blood pressure and calcium metabolism in elderly Chinese. Chin J Physiol 1993;36:85-94. [PubMed: 8198625]

35. Scragg R, Khaw KT, Murphy S. Effect of winter oral vitamin D3 supplementation on cardiovascular risk factors in elderly adults. Eur J Clin Nutr 1995;49:640-6. [PubMed: 7498100]

36. Lacroix AZ, Kotchen J, Anderson G, et al. Calcium plus vitamin D supplementation and mortality in postmenopausal women: the Women's Health Initiative calcium-vitamin D randomized controlled trial. J Gerontol A Biol Sci Med Sci 2009;64:559-67. [PubMed: 19221190]

37. Trivedi DP, Doll R, Khaw KT. Effect of four monthly oral vitamin D3 (cholecalciferol) supplementation on fractures and mortality in men and women living in the community: randomised double blind controlled trial. BMJ 2003;326:469. [PubMed: 12609940]

38. Vieth R, Bischoff-Ferrari H, Boucher BJ, et al. The urgent need to recommend an intake of vitamin D that is effective. Am J Clin Nutr 2007;85:649-50. [PubMed: 17344484]

39. Zittermann A, Schleithoff SS, Koerfer R. Vitamin D and vascular calcification. Curr Opin Lipidol 2007;18:41-6. [PubMed: 17218831]

40. Fitzpatrick LA, Bilezikian JP, Silverberg SJ. Parathyroid hormone and the cardiovascular system. Curr Osteoporos Rep 2008;6:77-83. [PubMed: 18778568]

41. Li YC, Kong J, Wei M, et al. 1,25-Dihydroxyvitamin D(3) is a negative endocrine regulator of the renin-angiotensin system. J Clin Invest 2002;110:229-38. [PubMed: 12122115]

42. Qiao G, Kong J, Uskokovic M, et al. Analogs of 1alpha,25-dihydroxyvitamin D(3) as novel inhibitors of renin biosynthesis. J Steroid Biochem Mol Biol 2005;96:59-66. [PubMed: 15878826]

43. Yuan W, Pan W, Kong J, et al. 1,25-Dihydroxyvitamin D3 suppresses renin gene transcription by blocking the activity of the cyclic AMP response element in the renin gene promoter. J Biol Chem 2007;282:29821-30. [PubMed: 17690094]

44. Norman AW, Frankel JB, Heldt AM, et al. Vitamin D deficiency inhibits pancreatic secretion of insulin. Science 1980;209:823-5. [PubMed: 6250216]

45. Mathieu C, Gysemans C, Giulietti A, et al. Vitamin D and diabetes. Diabetologia 2005;48:1247-57. [PubMed: 15971062]

46. Liu E, Meigs JB, Pittas AG, et al. Plasma 25-hydroxyvitamin d is associated with markers of the insulin resistant phenotype in nondiabetic adults. J Nutr 2009;139:329-34. [PubMed: 19106328]

47. Scragg R, Sowers M, Bell C. Serum 25-hydroxyvitamin D, diabetes, and ethnicity in the Third National Health and Nutrition Examination Survey. Diabetes Care 2004;27:2813-8. [PubMed: 15562190]

48. Chonchol M, Scragg R. 25-Hydroxyvitamin D, insulin resistance, and kidney function in the Third National Health and Nutrition Examination Survey. Kidney Int 2007;71:134-9. [PubMed: 17082756]

49. Mattila C, Knekt P, Männistö S, et al. Serum 25-hydroxyvitamin D concentration and subsequent risk of type 2 diabetes. Diabetes Care 2007;30:2569-70. [PubMed: 17626891]

50. Pittas AG, Harris SS, Stark PC, et al. The effects of calcium and vitamin D supplementation on blood glucose and markers of inflammation in nondiabetic adults. Diabetes Care 2007;30:980-6. [PubMed: 17277040]

51. Rahman A, Hershey S, Ahmed S, et al. Heart extracellular matrix gene expression profile in the vitamin D receptor knockout mice. J Steroid Biochem Mol Biol 2007;103:416-9. [PubMed: 17275288] 
52. Tishkoff DX, Nibbelink KA, Holmberg KH, et al. Functional vitamin D receptor (VDR) in the ttubules of cardiac myocytes: VDR knockout cardiomyocyte contractility. Endocrinology 2008;149:558-64. [PubMed: 17974622]

53. Simpson RU, Hershey SH, Nibbelink KA. Characterization of heart size and blood pressure in the vitamin D receptor knockout mouse. J Steroid Biochem Mol Biol 2007;103:521-4. [PubMed: 17275289]

54. London GM, Guérin AP, Verbeke FH, et al. Mineral metabolism and arterial functions in end-stage renal disease: potential role of 25-hydroxyvitamin D deficiency. J Am Soc Nephrol 2007;18:61320. [PubMed: 17202417]

55. Artaza JN, Norris KC. Vitamin D reduces the expression of collagen and key profibrotic factors by inducing an antifibrotic phenotype in mesenchymal multipotent cells. J Endocrinol 2009;200:20721. [PubMed: 19036760]

56. Sugden JA, Davies JI, Witham MD, et al. Vitamin D improves endothelial function in patients with type 2 diabetes mellitus and low vitamin D levels. Diabet Med 2008;25:320-5. [PubMed: 18279409]

57. Schleithoff SS, Zittermann A, Tenderich G, et al. Vitamin D supplementation improves cytokine profiles in patients with congestive heart failure: a double-blind, randomized, placebo-controlled trial. Am J Clin Nutr 2006;83:754-9. [PubMed: 16600924]

58. Alsafwah S, Laguardia SP, Nelson MD, et al. Hypovitaminosis D in African Americans residing in Memphis, Tennessee with and without heart failure. Am J Med Sci 2008;335:292-7. [PubMed: 18414068] 